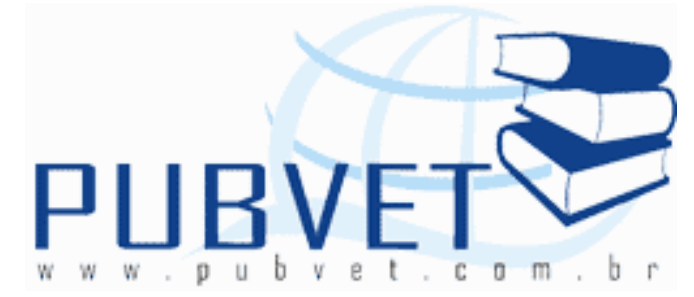

PUBVET, Publicações em Medicina Veterinária e Zootecnia.

\title{
Desenvolvimento pecuário brasileiro no agronegócio mundial
}

\author{
Carlos Rosa Godoi ${ }^{1}$; Lucilia Aparecida da Silva ${ }^{2}$; Ednea Freitas Portilho Silva ${ }^{2}$ \\ ${ }^{1}$ Zootecnista pela Fesurv - Universidade de Rio Verde, Rio Verde, GO. \\ ${ }^{2}$ Prof. Fac. Med. Vet. - Universidade de Rio Verde, Rio Verde, GO.
}

\section{Resumo}

O objetivo desta revisão é demonstrar o crescimento do agronegócio brasileiro nas últimas décadas e perspectivas para os próximos anos. Hoje o agronegócio, entendido como a soma dos setores produtivos com os de processamento do produto final e os de fabricação de insumos, é responsável por $33 \%$ do Produto Interno Bruto (PIB), $42 \%$ das exportações totais e $37 \%$ dos empregos brasileiros. O crescimento da população mundial pode favorecer a ascensão do Brasil como uma potência de agronegócios, para atender um maior volume de habitantes. A produção brasileira de alimentos deverá aumentar $70 \%$ entre 2006 e 2050. Vários fatores contribuem para que haja grandes chances, a longo prazo, do Brasil aumentar sua produção agrícola (principalmente de soja e milho). A indústria de rações é um dos maiores e mais dinâmico segmento do agronegócio brasileiro, responsável pelo consumo de mais de $60 \%$ da produção de milho, $35 \%$ da produção de soja e quantidades expressivas de outros grãos. A produção de rações tem grande importância, pois está, diretamente atrelada à avicultura e suinocultura, e estes dois setores, juntos, consomem $80 \%$ das rações produzidas no Brasil. A pecuária bovina nacional, com 209 milhões de cabeças destaca-se no cenário 
mundial, com grande importância econômica, o rebanho bovino mundial está estimado em pouco mais de 1 bilhão de animais, sendo a Índia o maior detentor, com 330.250 milhões de cabeças.

Palavras-chave: Produção, rebanho, população e crescimento

\title{
Brazilian livestock development in agribusiness world
}

\begin{abstract}
This review aims to demonstrate the growth of agribusiness in recent decades and the outlook for the coming years. Today, agribusiness, understood as the sum of productive sectors with the processing of the final product and manufacturing inputs, accounting for nearly one third of GDP in Brazil and similar value of the country's total exports, accounting for $33 \%$ of Gross Domestic Product (GDP), $42 \%$ of total exports and $37 \%$ of jobs in Brazil. The world population growth may encourage the rise of Brazil as a power of agribusiness to meet a higher volume of population, food production must increase $70 \%$ between 2006 and 2050. Several factors contribute to that there are great chances in the long run, from Brazil to increase its agricultural production (mainly soya and maize). The feed industry is one of the largest and most dynamic segment of agribusiness responsible for consuming more than $60 \%$ of maize production, $35 \%$ of the production of large quantities of soybeans and other grains, the production of feed is of great importance, because it directly linked to poultry and swine, these two sectors together consume $80 \%$ of the diets produced in Brazil. In cattle country, with 209 million head stands in the world scene with great economic importance, the world cattle herd is estimated at just over one billion animals, India's largest holder, with 330,250 million head.
\end{abstract}

Keywords: Production, livestock, and population growth 


\section{INTRODUÇÃO}

A explosão demográfica, e a produção de alimentos não somente acompanhou o crescimento da população como aumentou a disponibilidade, per capita, de alimentos. A população mundial saltou de 2,5 bilhões de pessoas em 1950, para 6,0 bilhões em 2000, um aumento de $240 \%$. Este crescimento ocorreu, principalmente, nos países em desenvolvimento onde a população passou de 1,7 bilhões para 5 bilhões de pessoas (294\%), a população mundial atualmente com 7 bilhões de habitantes representa um aumento de 752 milhões de pessoas para serem alimentadas. Esta população adicional pode representar a necessidade de se adicionar mais 78 milhões de hectares ao sistema produtivo, num espaço de tempo de 10 anos (FAO, 2000).

Nos últimos 20 anos, os níveis tecnológicos alcançados pelos produtores rurais brasileiros atingiram patamares expressivos que podem ser mensurados pelo aumento da produtividade no campo. Isso explica, por exemplo, o fato de o Brasil ter conseguido dobrar a produção de grãos para os atuais 100 milhões de toneladas, em relação à colheita de 50,8 milhões de toneladas obtida no início da década de 80, com a mesma área plantada. Hoje o agronegócio, entendido como a soma dos setores produtivo, de processamento do produto final e o de fabricação de insumos, responde por quase um terço do PIB do Brasil e por valor semelhante das exportações totais do país (GUANZIROLI, 2006).

O Brasil classifica-se mundialmente, como o segundo maior rebanho comercial do mundo e o maior exportador mundial e ainda o segundo em quantidade de equivalente carcaça produzida, perdendo somente para os Estados Unidos da América do Norte em volume produzido. A produção de equivalente carcaça aumentou mais de $20 \%$ enquanto as exportações quadruplicaram aproximadamente 140 países compram hoje a carne bovina brasileira (FILHO, 2006). 
Em 2003, o País dividiu a liderança do comércio exportador mundial de carne com a Austrália, as previsões apontam para uma consolidação do Brasil como maior exportador mundial de carne bovina. (ANUALPEC, 2004).

A produção de rações tem grande importância, pois está diretamente atrelado à avicultura e suinocultura. Estes dois setores, juntos, consomem 80\% das rações produzidas no Brasil (SINDIRAÇÕES, 2006).

A ovinocultura brasileira tem passado por profundas transformações desde a última década, imposta em grande parte pela competitividade gerada por um cenário internacional marcado pela queda de fronteiras políticoeconômicas, criação de mercados comuns e a globalização da economia (JUNIOR et al., 2004).

No Nordeste brasileiro, a caprinocultura tem-se mostrado como uma importante atividade sócio-econômica, com destaque para a agricultura familiar. Recebendo nos últimos anos investimentos privados e governamentais, para o desenvolvimento de tecnologias regionais. O estado da Bahia possui a maior população caprina e a segunda maior população ovina do Brasil (QUADROS, 2005). O objetivo desta revisão é demonstrar o crescimento do agronegócio brasileiro nas ultimas décadas e perspectivas para os próximos anos.

\section{SITUAÇÃO DO AGRONEGÓCIO NO MUNDO}

O rebanho bovino mundial está estimado em pouco mais de 1 bilhão de animais, sendo a Índia o maior detentor, com 330.250 milhões; todavia não comercial e sim por razões religiosas. A produção mundial de carne bovina, está concentrada em dezesseis maiores produtores, encontrando-se estabilizada nos últimos anos em pouco mais de 50 milhões de toneladas equivalente carcaças, e com pequena variação no consumo mundial (RODRIGUES, 2008).

Os potenciais de aumento significativo, em condições normais, estão concentrados na Ásia, mais particularmente na China, pelo crescimento 
contínuo e devido à abertura da sua economia. Todavia esse potencial é de outra forma limitado a mudança de hábito alimentar, aumento difuso da renda per capita, limitações geográficas e climáticas para aumento da produção interna e, especialmente, em razão do grande protecionismo comercial contra importações praticadas largamente naquele país (RODRIGUES, 2008).

Rodrigues (2008) descreve ainda que o Brasil ocupa, progressivamente, posição de destaque na produção de pecuária de corte e no mercado internacional da produção e exportação de carne, firmando-se nos últimos dois anos como o maior exportador de carne mundial. Possui também o maior rebanho bovino comercial do mundo, e detém inegavelmente o maior potencial de aumento e diversificação de produção e exportação; sendo o único país que pode aumentar ou até dobrar a produção e exportação de carnes sem afetar seu próprio mercado interno. Este mesmo autor afirma que essa capacidade é baseada no enorme aumento do rebanho e dos índices de produtividade, das áreas e diversificação de pastagens e disponibilidade de grãos e insumos, do avanço tecnológico de técnicas produtivas e diversificação genética das raças zebuínas. Além disso, o Brasil ainda detém a maior reserva de áreas agricultáveis de cerrado, sem interferência da região amazônica.

\section{SITUAÇÃO DO AGRONEGÓCIO NO BRASIL}

Vários fatores contribuem para que haja grandes chances, a longo prazo, do Brasil aumentar sua produção agrícola (principalmente de soja e milho). Pelo lado da oferta cabe destacar que o Brasil possui grandes áreas ainda inexploradas ou deficientemente exploradas que poderão ser incorporadas à produção agrícola no futuro se houver investimentos em produtividade e em meios de escoamento das safras (GUANZIROLI, 2006).

O crescimento da população mundial pode favorecer a ascensão do Brasil como uma potência de agronegócios, para atender um maior volume de habitantes, a produção de alimentos deverá aumentar 70\% entre 2006 e 
2050, segundo estimativas da Organização das Nações Unidas para a Alimentação e a Agricultura (FAO, 2010).

O agronegócio é responsável por 33\% do Produto Interno Bruto (PIB), $42 \%$ das exportações totais e $37 \%$ dos empregos brasileiros (MAPA, 2004).

No Brasil, a produção de carne bovina teve um aumento de $21,5 \%$ no período de 1995 a 2003, passando de 6 milhões para 7,3 milhões de toneladas. O aumento da produção tem possibilitado abastecer o mercado doméstico, reduzindo a dependência das exportações para complementar o abastecimento interno, bem como gerar excedentes exportáveis. 0 crescimento na produção brasileira de carne se deve a fatores como investimentos em novas tecnologias da genética, sanidade, manejo, gerenciamento e nutrição (GUANZIROLI, 2006).

Transformações intensas marcaram a pecuária de corte brasileira na última década. Essas transformações levaram a alterações importantes em toda a cadeia desde a produção até o consumo, cadeia esta, que tem um peso significativo na formação do PIB brasileiro, gerando somente em divisas mais de 5,5 bilhões de dólares com as exportações de carne, calçados e couros (FILHO, 2006).

De acordo com Garcia et al. (2006), a produção de carne de cordeiro no Brasil vem sendo cada vez mais procurada pelos produtores, devido a lucratividade que a atividade pode proporcionar. Este estímulo relacionado à maior produção de cordeiros resultou no aumento dos números de animais abatidos no Brasil.

A distribuição do rebanho brasileiro de caprinos é desigual entre as regiões. Para a região Nordeste, que representa menos de $20 \%$ da área territorial brasileira, a concentração, em 2003, foi de 8,53 milhões de cabeças, que representam $89 \%$ do rebanho efetivo no País. Esse fato é explicado pela capacidade de adaptação do caprino às condições ecológicas do semi-árido nordestino e às características edafoclimática e vegetativas, propiciando condições para o desenvolvimento da espécie (SAMPAIO et al., 2006). O 
estado da Bahia representa a maior população caprina e a segunda maior ovina do Brasil (QUADROS, 2005).

As atividades relacionadas à suinocultura ocupam lugar de destaque na matriz produtiva do agronegócio brasileiro, destacando-a como uma atividade de importância no âmbito econômico e social. Segundo estimativas, mais de 730 mil pessoas dependem diretamente da suinocultura, sendo essa atividade responsável pela renda de mais de 2,7 milhões de pessoas (ROPPA, 2002).

Nos últimos anos, a suinocultura, no Brasil, tem ganhado ainda mais importância, principalmente no mercado internacional, por algumas vantagens comparativas que tornam a atividade competitiva no cenário externo. Com um sistema produtivo baseado na integração vertical, demanda pelas agroindústrias, e com disponibilidade de insumos básicos para a produção, principalmente de grãos essenciais como soja e milho, e investimentos em tecnologia, a produção de suínos no Brasil apresenta custos inferiores aos principais competidores mundiais (GONÇALVES \& PALMEIRAS, 2006).

Embora a carne suína seja a mais consumida em todo o mundo, os consumidores brasileiros dão preferência para as carnes de aves e de bovinos. A média de consumo de carne suína in natura no Brasil é $12,1 \mathrm{~kg} / \mathrm{hab} / \mathrm{ano}$, enquanto a média mundial é $14,5 \mathrm{~kg}$, e a européia é mais de $40 \mathrm{~kg}$. Preconceitos e falta de informação sobre a qualidade da carne suína podem ser as causas do baixo consumo (ABIPECS, 2004).

O Brasil sendo o maior produtor mundial de proteína animal tem no mercado interno o principal destino de sua produção. A produção brasileira de carnes (bovina, suína e de aves) em 2010, foi estimada em 24,5 milhões de toneladas, sendo $75 \%$ consumida internamente no país. O Ministério da Agricultura Pecuária e Abastecimento apontam ainda que no ano de 2010, o consumo per capita de carnes aumentou em relação ao ano anterior chegando a 37,4 kg para carne bovina; 43,9 kg de carne de aves e 14,1 kg de carne suína, refletindo o bom desempenho da economia brasileira. Também as carnes ovinas e caprinas, assim como a produção de leite e seus derivados, são consumidos majoritariamente no mercado interno brasileiro (MAPA, 2011). 
O País possui atualmente o terceiro maior rebanho mundial de suínos com mais de 32 milhões de cabeças, sendo superado apenas pelos Estados Unidos, com um rebanho superior a 60 milhões de animais, e pela China que possui o maior rebanho de suínos, com mais de 460 milhões de animais. 0 crescimento do rebanho de suínos no Brasil tem se mantido praticamente constante, enquanto que o número de matrizes suínas decresceu nos últimos dez anos. Por outro lado, a produção de leitões cresceu significativamente, passando de 22,4 milhões em 1993 para quase 30 milhões em 2002 (ANUALPEC, 2002).

A importância do segmento de produção de rações deve-se em grande parte ao fato de estar diretamente atrelado à avicultura e suinocultura como mostra a (tabela 1). Estes dois setores, juntos, consomem $80 \%$ das rações produzidas no Brasil. Em 2009 a demanda por espécie foi de 47\% para avicultura de corte, $8 \%$ avicultura de postura, 25\% suinocultura, $7 \%$ bovinocultura leiteira, $4 \%$ bovinocultura de corte. A avicultura e a suinocultura têm grande representatividade no agronegócio brasileiro, pois a ração representa cerca de $70 \%$ do custo de produção e, por isso, qualquer atitude que vise garantir aos animais dietas com nutrientes de quantidade e nas proporções requeridas, resultará em maior produtividade e retorno financeiro (SINDIRAÇÕES, 2006).

O Brasil é um dos maiores produtores de ração do mundo, responsável pela produção de 58,4 milhões de toneladas em 2009, perdendo apenas para Estados Unidos e China. A indústria de rações é um dos maiores e mais dinâmico segmento do agronegócio brasileiro, responsável pelo consumo de mais de $60 \%$ da produção de milho, $35 \%$ da produção de soja e quantidades expressivas de outros grãos. Além disso, ela é importante para a indústria química, uma vez que demanda a produção de grandes quantidades de vitaminas, aminoácidos e microingredientes diversos utilizados na alimentação animal. Considerando o total de 14,8 milhões de toneladas de rações produzido no ano de 1990 e a produção de 58,4 milhões de toneladas em 2009 a evolução foi de $394,6 \%$ (SINDIRAÇÕES, 2009). Conforme dados do 
(Sindirações, 2011), a produção brasileira de 2010 ficou em 61,4 milhões de toneladas, elevação de 5,3\% em relação o ano anterior, e a produção de ração de 2011 deve somar 66,6 milhões de toneladas, um crescimento de 4,7\% sobre o ano 2010.

TABELA 1 - Mostra a produção nacional de rações (milhões de ton/espécie) 2000-2008.

\begin{tabular}{llllllllll}
\hline ATIVIDADES & 2000 & $\mathbf{2 0 0 1}$ & $\mathbf{2 0 0 2}$ & $\mathbf{2 0 0 3}$ & 2004 & 2005 & 2006 & 2007 & 2008 \\
\hline Avicultura & $20.177,6$ & $21.755,6$ & $23.144,8$ & $24.190,0$ & $24.923,5$ & $26.771,1$ & $27.015,2$ & $29.703,5$ & $31.264,3$ \\
Corte & $16.865,9$ & $18.046,5$ & $19.194,8$ & $20.250,0$ & $20.841,7$ & $22.856,1$ & $23.391,9$ & $25.567,7$ & $27.025,1$ \\
Postura & $3.311,7$ & $3.709,1$ & $3.950,0$ & $3.940,0$ & $4.081,8$ & $3.915,0$ & $3.623,3$ & $4.135,8$ & $4.239,2$ \\
Suínos & $10.085,2$ & $12.050,3$ & $12.590,1$ & $13.221,9$ & $12.553,8$ & $12.392,8$ & $13.137,3$ & $14.195,3$ & $14.976,0$ \\
Bovinos & $2.468,7$ & $2.981,8$ & $3.619,8$ & $3.880,0$ & $5.165,0$ & $5.375,2$ & $5.320,6$ & $6.457,9$ & $7.168,2$ \\
Pet Food & $1.000,0$ & $1.172,0$ & $1.234,0$ & $1.300,0$ & $1.430,7$ & $1.562,4$ & $1.680,9$ & $1.848,7$ & $1.987,4$ \\
Equinos & 320,0 & 340,0 & 360,0 & 378,0 & 300,0 & 300,0 & 344,0 & 441,0 & 485,1 \\
Aquicultura & 126,8 & 162,0 & 202,3 & 247,5 & 260,0 & 218,2 & 226,8 & 224,7 & 224,7 \\
Outros & 280,0 & 350,0 & 443,1 & 470,0 & 300,0 & 589,0 & 640,0 & 681,6 & 708,9 \\
\hline Total & $\mathbf{3 4 . 4 5 8 , 3}$ & $\mathbf{3 8 . 8 1 1 , 7}$ & $\mathbf{4 1 . 5 9 4 , 1}$ & $\mathbf{4 3 . 6 8 7 , 4}$ & $\mathbf{4 4 . 9 3 3 , 0}$ & $\mathbf{4 7 . 2 0 8 , 7}$ & $\mathbf{4 8 . 3 6 4 , 8}$ & $\mathbf{5 3 . 5 5 2 , 7}$ & $\mathbf{5 6 . 8 1 4 , 6}$ \\
\hline
\end{tabular}

Fonte: Sindirações/UBA (2007-2008).

\subsection{Bovinocultura brasileira}

A pecuária bovina nacional, com 209,541 milhões de cabeças (Sepin (2011). Destaca-se no cenário mundial, sendo uma atividade de grande importância econômica, com indicadores que apontam seu fortalecimento como produtora de alimento de alta qualidade e geradora de divisas (EUCLIDES FILHO, 2000).

A bovinocultura de corte produziu 7,5 milhões de toneladas de carne em 2000, exportando 420 mil toneladas com um faturamento de US\$ 688 milhões e apresenta-se com tendência crescente na produção e exportação (BUTOLO, 2002). 
A produção de ração para bovinos de corte sofreu queda de $6,0 \%$ durante o ano de 2009, graças à redução expressiva de uso de tecnologia entre os produtores bovinos. Os motivos para o recuo nos programas de confinamento foram, além da crise, o câmbio valorizado e o congelamento de transações, o que colocou muitos frigoríficos em situação financeira frágil. $O$ descompasso entre o preço da arroba do boi e o preço do bezerro, e o acentuado índice de chuvas tardaram o confinamento e impactaram a queda no consumo total de ração e suplementos (SINDIRAÇÕES, 2009).

O Centro-Oeste brasileiro possui um rebanho bovino de aproximadamente 72 milhões de cabeças, com mais de $80 \%$ de zebuínos, grande parte das quais formadoras de plantéis de cria (IBGE, 2005).

Constata-se que cinco estados brasileiros detém 54\% do rebanho do país, são eles Mato Grosso do Sul, Minas Gerais, Mato Grosso, Goiás e o Pará, compreendendo 90 milhões de cabeças (BRANCO \& MAIA, S/D).

O efetivo nacional de bovinos em 2010 chegou a 209,541 milhões de cabeças, (Tabela 2 e 3) demonstra estes dados por Unidade da Federação, com um aumento de 2,1\% em relação a 2009 (205,308 milhões). Foram registrados aumentos nas regiões Norte $(4,1 \%)$, Centro-Oeste $(2,7 \%)$ Nordeste $(1,7 \%)$ e Sudeste $(0,6 \%)$. Na distribuição regional, $34,6 \%$ dos bovinos encontravam-se no Centro-Oeste, $20,1 \%$ no Norte e $18,3 \%$ no Sudeste (SEPIN, 2011).

Pereira \& Lima (2000), relatam que a pecuária representa $40 \%$ do valor do PIB da agropecuária, ocupa cerca de $26 \%$ da força de trabalho rural, tem uma taxa de crescimento anual de $3 \%$ e utiliza $3 / 4$ das terras totais ocupadas com a atividade agropecuária.

Segundo dados da Superintendência de Estatística Pesquisa e Informações Socioeconômicas Sepin (2011), o rebanho bovino goiano em 2010 somou 21,348 milhões de cabeças, com aumento de 2,3\%, ou seja, 472.938 animais a mais que em 2009. Com esse resultado o Estado mantém a $4^{a}$ posição de maior rebanho bovino nacional, atrás de Mato Grosso, Minas Gerais e Mato Grosso do Sul, conforme visto na Tabela 2. 
GODOI, C.R., SILVA, L.A. e SILVA, E.F.P. Desenvolvimento pecuário brasileiro no agronegócio mundial. PUBVET, Londrina, V. 6, N. 30, Ed. 217, Art. 1448, 2012.

TABELA 2 - Ranking do efetivo do rebanho bovino, por Unidade da Federação 2000, 2005 e 2010.

\begin{tabular}{|c|c|c|c|c|c|c|}
\hline \multirow[b]{2}{*}{ UF } & \multicolumn{6}{|c|}{ Bovino (Cabeças) } \\
\hline & 2000 & Rank & 2005 & Rank & 2010 & Rank \\
\hline Brasil & 169.875 .524 & & 207.156 .696 & & 209.541.109 & \\
\hline MT & 18.924 .532 & 30 & 26.651 .500 & 10 & 28.757 .438 & 10 \\
\hline MG & 19.975 .271 & 20 & 21.403 .680 & 30 & 22.698 .120 & $2^{\circ}$ \\
\hline MS & 22.205 .408 & 10 & 24.504 .098 & 20 & 22.354 .077 & 30 \\
\hline GO & 18.399 .222 & 40 & 20.726 .586 & 40 & 21.347 .881 & $4^{\circ}$ \\
\hline PA & 10.271 .409 & 70 & 18.063 .669 & 50 & 17.633.339 & 50 \\
\hline RS & 13.601 .000 & $5^{\circ}$ & 14.239 .906 & 60 & 14.469 .307 & $6^{\circ}$ \\
\hline RO & 5.664 .320 & $11^{\circ}$ & 11.349 .452 & $8^{\circ}$ & 11.842 .073 & 70 \\
\hline SP & 13.091 .946 & 60 & 13.420 .780 & 70 & 11.197 .697 & $8^{\circ}$ \\
\hline BA & 9.556 .752 & 90 & 10.463 .098 & 90 & 10.528 .419 & 90 \\
\hline PR & 9.645 .866 & $8^{\circ}$ & 10.153 .375 & $10^{\circ}$ & 9.411 .380 & $10^{\circ}$ \\
\hline TO & 6.142 .096 & $10^{\circ}$ & 7.961 .926 & $11^{\circ}$ & 7.994 .200 & $11^{\circ}$ \\
\hline MA & 4.093 .563 & $12^{\circ}$ & 6.448 .948 & $12^{\circ}$ & 6.979 .844 & $12^{\circ}$ \\
\hline SC & 3.051 .104 & $13^{\circ}$ & 3.376 .725 & $13^{\circ}$ & 3.985 .662 & $13^{\circ}$ \\
\hline$A C$ & 1.033 .311 & $19^{\circ}$ & 2.313 .185 & $14^{\circ}$ & 2.578 .460 & $14^{\circ}$ \\
\hline CE & 2.205 .954 & $14^{\circ}$ & 2.299.233 & $15^{\circ}$ & 2.546 .134 & $15^{\circ}$ \\
\hline PE & 1.515 .712 & $18^{\circ}$ & 1.909 .468 & $18^{\circ}$ & 2.383 .268 & $16^{\circ}$ \\
\hline ES & 1.825 .283 & $16^{\circ}$ & 2.026 .690 & $17^{\circ}$ & 2.195 .406 & 170 \\
\hline RJ & 1.959 .497 & $15^{\circ}$ & 2.092 .748 & $16^{\circ}$ & 2.160 .727 & $18^{\circ}$ \\
\hline PI & 1.779 .456 & 170 & 1.826 .833 & 190 & 1.679 .957 & $19^{\circ}$ \\
\hline AM & 843.254 & $22^{\circ}$ & 1.197 .171 & $20^{\circ}$ & 1.360 .800 & $20^{\circ}$ \\
\hline PB & 952.779 & $20^{\circ}$ & 1.052 .613 & $21^{\circ}$ & 1.242 .579 & $21^{\circ}$ \\
\hline$A L$ & 778.750 & $24^{\circ}$ & 985.422 & $23^{\circ}$ & 1.219 .578 & $22^{\circ}$ \\
\hline SE & 879.730 & $21^{\circ}$ & 1.005 .177 & $22^{\circ}$ & 1.117 .765 & $23^{\circ}$ \\
\hline RN & 803.948 & $23^{\circ}$ & 978.494 & $24^{\circ}$ & 1.064 .575 & $24^{\circ}$ \\
\hline $\mathrm{RR}$ & 480.400 & $25^{\circ}$ & 507.000 & $25^{\circ}$ & 577.050 & $25^{\circ}$ \\
\hline AP & 82.822 & $27^{\circ}$ & 96.599 & $27^{\circ}$ & 114.773 & $26^{\circ}$ \\
\hline$\overline{D F}$ & 112.139 & $26^{\circ}$ & 102.320 & $26^{\circ}$ & 100.600 & 270 \\
\hline
\end{tabular}

Fonte: IBGE.

Elaboração: SEGPLAN-GO / SEPIN / Gerência de Estatística Socioeconômica - 2011. 
GODOI, C.R., SILVA, L.A. e SILVA, E.F.P. Desenvolvimento pecuário brasileiro no agronegócio mundial. PUBVET, Londrina, V. 6, N. 30, Ed. 217, Art. 1448, 2012.

TABELA 3 - Efetiva do rebanho bovino, por Regiões da Federação - 2006 2009.

\begin{tabular}{|c|c|c|c|c|}
\hline \multirow{3}{*}{ Brasil } & \multicolumn{4}{|c|}{ Bovino (Cabeças) } \\
\hline & 2006 & 2007 & 2008 & 2009 \\
\hline & 205.886 .244 & 199.752 .014 & 202.306.731 & 205.307.954 \\
\hline \multicolumn{5}{|c|}{ Regiões } \\
\hline \multicolumn{5}{|c|}{ NORTE } \\
\hline PA & 17.501 .678 & 15.353 .989 & 16.240 .697 & 16.856 .561 \\
\hline RO & 11.484 .162 & 11.007 .613 & 11.176 .201 & 11.532 .891 \\
\hline TO & 7.760 .590 & 7.395 .450 & 7.392 .515 & 7.605 .249 \\
\hline$A M$ & 1.243 .358 & 1.208 .652 & 1.312 .352 & 1.350 .816 \\
\hline$A C$ & 2.452 .915 & 2.315 .798 & 2.425 .687 & 2.511 .285 \\
\hline RR & 508.600 & 481.100 & 476.200 & 475.380 \\
\hline AP & 109.081 & 103.170 & 95.803 & 104.977 \\
\hline \multicolumn{5}{|c|}{ NORDESTE } \\
\hline BA & 10.764 .857 & 11.385 .723 & 11.099 .880 & 10.230 .469 \\
\hline MA & 6.613 .270 & 6.609 .438 & 6.816 .338 & 6.885 .265 \\
\hline PI & 1.838 .378 & 1.736 .520 & 1.750 .910 & 1.682 .111 \\
\hline CE & 2.352 .589 & 2.424 .290 & 2.460 .523 & 2.494 .482 \\
\hline PE & 2.095 .184 & 2.219 .892 & 2.249 .788 & 2.297 .366 \\
\hline PB & 1.092 .792 & 1.139 .322 & 1.202 .363 & 1.236 .276 \\
\hline RN & 1.027 .289 & 1.010 .238 & 1.029 .240 & 1.150 .028 \\
\hline SE & 1.067 .508 & 1.073 .692 & 1.080 .833 & 1.120 .832 \\
\hline $\mathrm{AL}$ & 1.029 .352 & 1.112 .125 & 1.162 .005 & 1.193 .021 \\
\hline \multicolumn{5}{|c|}{ SUDESTE } \\
\hline MG & 22.203 .154 & 22.575 .194 & 22.369 .639 & 22.469 .791 \\
\hline SP & 12.790 .383 & 11.790 .564 & 11.185 .556 & 11.197 .605 \\
\hline RJ & 2.095 .666 & 2.078 .529 & 2.144 .882 & 2.162 .043 \\
\hline ES & 2.119 .309 & 2.142 .342 & 2.120 .017 & 2.187 .235 \\
\hline \multicolumn{5}{|c|}{ SUL } \\
\hline RS & 13.974 .827 & 13.516 .426 & 14.115 .643 & 14.366 .298 \\
\hline PR & 9.764 .545 & 9.494 .843 & 9.585 .600 & 9.562 .113 \\
\hline SC & 3.460 .835 & 3.488 .992 & 3.884 .264 & 3.976 .165 \\
\hline \multicolumn{5}{|c|}{ CENTRO OESTE } \\
\hline MS & 23.726 .290 & 21.832 .001 & 22.365 .219 & 22.325 .663 \\
\hline MT & 26.064 .332 & 25.683 .031 & 26.018 .216 & 27.357 .089 \\
\hline GO & 20.646 .560 & 20.471 .490 & 20.466 .360 & 20.874 .943 \\
\hline$\overline{D F}$ & 98.740 & 101.590 & 80.000 & 102.000 \\
\hline
\end{tabular}

Fonte: IBGE.

Elaboração: SEGPLAN-GO / SEPIN / Gerência de Estatística Socioeconômica - 2011. 
A cadeia produtiva de leite movimenta anualmente US\$10 bilhões e emprega três milhões de pessoas, das quais acima de um milhão são produtores que produzem 21 bilhões de litros de leite/ano, provenientes de um dos maiores rebanhos do mundo, que corresponde por $82 \%$ do consumo nacional de leite, sendo o restante complementado com importação. Comparativamente a outros países produtores de leite, o Brasil tem a menor produtividade leiteira, que tem como origem, fatores de ordem técnica, política, econômica e social. O setor leiteiro tem se ajustado às transformações na economia, com novas tecnologias e ampliação da fronteira agrícola às regiões de maior potencial produtivo e de menores custos de produção, fazendo com que a partir de 1994 a produção nacional do leite tenha acima da média histórica (BUTOLO, 2002).

A pecuária leiteira sofreu diante do descompasso entre receita e custos de produção, nível de captação, preço do leite no varejo e queda na demanda durante o ano de 2009, situação que ainda não está em equilíbrio. Isso fez com que houvesse redução no uso de tecnologia e queda de $7,9 \%$ no consumo de ração. Outro impacto negativo sofrido pelo setor foi o da competição de leite em pó proveniente da Argentina e do Uruguai, em um momento em que a produção local era suficiente para atender à demanda local (SINDIRAÇÕES, 2009).

Segundo dados do Sepin (2011) a produção nacional de leite em 2010, atingiu a marca de 30,715 bilhões de litros, um acréscimo de 5,6\% em relação ao ano anterior. Os principais produtores foram Minas Gerais 27,3\%, Rio Grande do Sul 11,8\%, Paraná 11,7\% e Goiás 10,4\%.

\subsection{Avicultura}

A avicultura brasileira de corte (Tabela 4) mostra que a produção em 2000, foi de 5,977 milhões de toneladas de carne mantendo o Brasil como segundo maior produtor mundial e sua exportação ficou próxima de 950 mil toneladas com um faturamento próximo aos US\$900 milhões com um 
GODOI, C.R., SILVA, L.A. e SILVA, E.F.P. Desenvolvimento pecuário brasileiro no agronegócio mundial. PUBVET, Londrina, V. 6, N. 30, Ed. 217, Art. 1448, 2012.

aumento de $14,16 \%$ em relação ao ano anterior, ficando no ranking mundial como o segundo exportador mundial. O consumo interno próximo de 30,0 $\mathrm{kg} /$ per capita manteve-se estável comparado ao ano anterior (Tabela 5), colocando-nos entre os sete maiores consumidores mundiais de carne de frango (BUTOLO, 2002).

TABELA 4 - Evolução da produção brasileira de carne de frango (em mil tonelada).

\begin{tabular}{|c|c|c|c|c|c|c|}
\hline Ano & $\begin{array}{c}\mathrm{A}= \\
\text { Produção } \\
\text { (mil } \\
\text { toneladas) }\end{array}$ & $\begin{array}{c}\text { Evolução } \\
\text { da } \\
\text { produção } \\
(\%)\end{array}$ & $\begin{array}{c}\mathrm{B}= \\
\text { Consumo } \\
\text { (mil } \\
\text { toneladas) }\end{array}$ & $\begin{array}{c}\text { Evolução } \\
\text { do } \\
\text { consumo } \\
(\%)\end{array}$ & $\begin{array}{c}\mathrm{C}= \\
\text { Exportação } \\
\text { (mil } \\
\text { toneladas) }\end{array}$ & $\begin{array}{c}\text { Evolução } \\
\text { da } \\
\text { exportação } \\
(\%)\end{array}$ \\
\hline 1988 & 1.947 & 8,29 & 1.706 & 7,70 & 241 & 12,38 \\
\hline 1989 & 2.082 & 6,93 & 1.839 & 7,80 & 243 & 11,67 \\
\hline 1990 & 2.356 & 13,16 & 2.057 & 11,85 & 299 & 12,69 \\
\hline 1991 & 2.627 & 11,50 & 2.306 & 12,11 & 321 & 12,22 \\
\hline 1992 & 2.872 & 9,33 & 2.500 & 8,41 & 372 & 12,95 \\
\hline 1993 & 3.144 & 9,47 & 2.727 & 9,08 & 417 & 13,26 \\
\hline 1994 & 3.491 & 11,04 & 3.010 & 10,38 & 481 & 14,70 \\
\hline 1995 & 4.050 & 16,01 & 3.620 & 20,27 & 430 & 10,60 \\
\hline 1996 & 4.058 & 0,20 & 3.489 & $-3,62$ & 569 & 14,02 \\
\hline 1997 & 4.461 & 9,93 & 3.812 & 9,25 & 649 & 14,06 \\
\hline 1998 & 4.853 & 8,79 & 4.242 & 11,28 & 611 & $-5,86$ \\
\hline 1999 & 5.526 & 13,87 & 4.756 & 12,12 & 770 & 26,02 \\
\hline 2000 & 5.977 & 8,16 & 5.070 & 6,60 & 907 & 17,79 \\
\hline 2001 & 6.735 & 12,70 & 5.486 & 8,26 & 1.249 & 37,78 \\
\hline 2002 & 7.517 & 11,60 & 5.917 & 7,85 & 1.600 & 28,07 \\
\hline 2003 & 7.843 & 4,34 & 5.921 & 0,07 & 1.922 & 20,13 \\
\hline 2004 & 8.494 & 8,30 & 6.069 & 2,51 & 2.469 & 26,14 \\
\hline 2005 & 9.297 & 9,46 & 6.535 & 7,68 & 2.845 & 15,23 \\
\hline 2006 & 9.336 & 0,41 & 6.623 & 1,34 & 2.713 & $-4,67$ \\
\hline 2007 & 10.246 & 9,75 & 6.959 & 5,09 & 3.287 & 21,16 \\
\hline 2008 & 10.880 & 6,19 & 7.300 & 4,90 & 3.580 & 8,92 \\
\hline
\end{tabular}

Fonte: UBA/ABEF (2007-2008) 
De acordo com levantamento da Sindirações (2009) a avicultura de corte, é o setor de maior demanda de ração animal no país, registrou crescimento de $0,8 \%$ em 2009 em comparação com o ano de 2008. O produto de exportação brasileiro perdeu competitividade durante o ano, graças ao câmbio valorizado, o que forçou a queda no preço interno e na rentabilidade dos produtores. A margem menor fez com que houvesse redução no consumo de tecnologia nutricional. A expectativa para 2010 é que o setor encontre novas oportunidades e mercados, o que deve impactar positivamente a demanda por rações e tecnologia nutricional.

TABELA 5 - Consumo per capita no Brasil (1988-2007).

\begin{tabular}{lcccc}
\hline Anos & Ovos (unid) & Frangos $(\mathrm{kg})$ & Bovinos $(\mathrm{kg})$ & Suínos $(\mathrm{kg})$ \\
\hline 1988 & 103,0 & 11,8 & 27,6 & 7,0 \\
1989 & 83,0 & 12,4 & 33,8 & 6,6 \\
1990 & 89,0 & 14,2 & 36,1 & 7,2 \\
1991 & 88,0 & 15,7 & 38,0 & 7,6 \\
1992 & 88,0 & 16,8 & 38,9 & 7,9 \\
1993 & 86,0 & 18,1 & 37,0 & 8,3 \\
1994 & 92,0 & 19,2 & 36,4 & 8,4 \\
1995 & 101,0 & 23,3 & 39,3 & 9,2 \\
1996 & 101,0 & 22,2 & 41,4 & 9,6 \\
1997 & 82,0 & 24,0 & 39,0 & 9,3 \\
1998 & 85,2 & 26,3 & 37,5 & 9,9 \\
1999 & 89,3 & 29,1 & 35,6 & 10,7 \\
2000 & 94,0 & 29,9 & 36,5 & 10,9 \\
2001 & 94,0 & 31,8 & 37,2 & 10,9 \\
2002 & 130,0 & 33,8 & 35,8 & 13,8 \\
2003 & 127,0 & 33,3 & 35,6 & 12,4 \\
2004 & 130,0 & 33,9 & 35,9 & 12,1 \\
2005 & 138,0 & 35,4 & 36,3 & 11,3 \\
2006 & 142,3 & 37,0 & 36,6 & 12,7 \\
2007 & 131,8 & 37,8 & 36,2 & 13,0 \\
\hline Fonte: & 13,0 & &
\end{tabular}

Fonte: CNPC/ABEF/ABIPECS/UBA, (2007-2008). 
Segundo dados de BUTOLO (2002) a produção de ovos foi de 14,8 bilhões de unidade com um consumo per capita próximo de 90 ovos, mantendo - Brasil como o sétimo produtor mundial. No tocante aos valores de comercialização dos produtos finais, frangos e ovos, consumidos internamente ou exportados, a avicultura brasileira atingiu valores de US\$ 6,8 bilhões correspondendo a $0,78 \%$ do Produto Interno Bruto (PIB).

\subsection{Suinocultura}

Em todo o ano de 2009, houve redução no uso de tecnologia, em parte compensada pela maior adição de milho, cujo preço foi bastante atrativo. Buscando controle nos custos de produção, o produtor optou por aumentar a parcela do grão na composição da ração e reduzir o uso de premix (SINDIRAÇÕES, 2009).

A suinocultura é uma atividade que propicia ótimas oportunidades para investimentos e possibilita transformar matéria-prima bruta (milho) em produtos de maior valor agregado, como carne e derivados industrializados, agregando a cada tonelada de carne exportada, 3,53 toneladas de milho. Desta forma, exportar carne suína significa incrementar a exportação de grãos e mão de obra (BUTOLO, 2002).

Apesar de ter sido influenciado pela crise, sofrendo com baixa rentabilidade e preços no mercado internacional, a suinocultura conseguiu aumentar os embarques em 2009, registrando também maior produtividade das matrizes. O consumo de ração para suínos foi praticamente o mesmo do demandado em 2008, apesar da flagrante queda na mobilização de tecnologia nutricional (SINDIRAÇÕES, 2009). De acordo com a mesma fonte as expectativas, porém, são otimistas para o setor com projeção de crescimento de $3 \%$ na produção de carne suína em 2010 , graças ao aumento esperado na demanda internacional e a campanhas de aumento no consumo doméstico. A produção de rações para suínos deve acompanhar essa demanda no próximo ano, o que pode significar recuperação para o setor de premix. 


\subsection{Ovinocultura}

A criação de ovinos com o propósito de produzir carne surge como uma boa alternativa para as propriedades rurais em diversas regiões brasileiras (MOTTA et al., 2001). De acordo com (OTTO et al.,1997) a produção de carne ovina é uma atividade econômica de grande importância para o país, entretanto, em determinadas regiões do Brasil, ela ainda é mal explorada.

A ovinocultura está presente em todos os continentes, em áreas com as mais diversas características edafoclimáticas. No entanto, apenas em alguns países apresenta expressão econômica, adotando, na maioria dos casos, baixos níveis de tecnologia e, conseqüentemente, obtendo baixa rentabilidade (NOGUEIRA FILHO, 2003).

O mercado da carne de ovinos é altamente promissor e a atividade vem crescendo a passos largos, em todas as regiões do país, destacando-se as regiões nordeste, norte e centro oeste. $O$ consumo de carnes e derivados no país é altamente favorável à ovinocultura, encontra-se em pleno processo de expansão, pois as estatísticas oficiais mostram um consumo médio de 0,700 $\mathrm{kg} / \mathrm{habitante/ano} \mathrm{(COUTO,} \mathrm{2001).}$

A atual situação do consumo está mudando, em virtude da direção que o mercado tomou, pois a carne hoje produzida está direcionada a um mercado existente nas grandes cidades, onde o poder aquisitivo da população é maior, exigindo carne de qualidade, cortes especiais e continuidade no abastecimento (MEDEIROS, 2001).

Silva (2002) afirma que é difícil precisar o consumo de carne ovina no Brasil, em função do elevado nível de consumo nas propriedades rurais. Estima-se entre 0,6 e $1 \mathrm{~kg}$ por habitante por ano o consumo brasileiro de carne ovina. Por outro lado, (CIDRÃO, 2006) relata que nas grandes cidades do país constata-se o aumento na procura pela carne ovina, pois o consumidor tem modificado o hábito de consumo, atento aos problemas relacionados à saúde, exigindo qualidade, palatabilidade, maciez e menores teores de gordura, dando preferência para as carnes magras. 
Segundo os dados do IBGE (2006), em 2005, o Brasil apresentava um rebanho ovino de 15.588 .041 cabeças ficando em $18^{\circ}$ lugar na posição mundial. Houve uma redução de $15,95 \%$ na evolução do rebanho ovino no Brasil no período de 1997 a 2005. Ao contrário deste panorama, a ovinocultura na região centro-oeste, no mesmo período, aumentou em torno de 94,92\%, contendo 937.782 cabeças.

A região Sul do Brasil, onde predominam as raças lanadas, mostrou uma queda de $50,1 \%$ do rebanho ovino entre 1980 e 2001, enquanto nas regiões onde predominam as raças deslanadas verificaram-se aumentos de efetivo de $227,8 \%$ para a região Norte, $238,2 \%$ para o Centro-Oeste e $13,5 \%$ para o Nordeste (COUTO, 2003).

Enquanto que em todo o País, nos anos de 1982 a 1994 o consumo de carne ovina aumentou em $5,4 \%$ ao ano, neste mesmo período o crescimento da população humana foi de apenas $2,1 \%$ ao ano. Nos países em desenvolvimento o consumo da carne ovina continuará crescendo em torno de $2,8 \%$ ao ano até 2020 . Nessas condições, a ovinocultura vem se tornando uma prioridade no Brasil, sendo uma alternativa para a geração de emprego e renda (BARROS \& VASCONCELOS, 2002).

O efetivo de ovinos em 2010 somou 17,4 milhões de cabeças, (Tabela 6), aumento de 3,4\% comparativamente a 2009. O maior rebanho da ovinocultura encontrava-se no Nordeste Brasileiro, com $56,7 \%$ do total nacional (IBGE, 2010).

Em relação ao rebanho mundial de ovinos, a China detém a maior criação com 170.882.215 cabeças, seguido da Austrália com 100.100.00 e da Índia com 62.500 .00 animais, números estes expressivos se levado em consideração o rebanho mundial de 1.135 .607 .422 de animais (FAO, 2007). 
GODOI, C.R., SILVA, L.A. e SILVA, E.F.P. Desenvolvimento pecuário brasileiro no agronegócio mundial. PUBVET, Londrina, V. 6, N. 30, Ed. 217, Art. 1448, 2012.

TABELA 6 - Efetiva de ovinos no Brasil, por Unidade da Federação 2003 e 2010.

\begin{tabular}{|c|c|c|}
\hline \multirow{3}{*}{$\begin{array}{l}\text { ANO } \\
\text { BRASIL }\end{array}$} & 2003 & 2010 \\
\hline & \multicolumn{2}{|c|}{ NÚMEROS DE ANIMAIS } \\
\hline & 14.784 .958 & 17.380 .581 \\
\hline \multicolumn{3}{|l|}{ ESTADOS } \\
\hline Acre & 45.479 & 81.072 \\
\hline Alagoas & 99.326 & 202.773 \\
\hline Amapá & 1.323 & 2.328 \\
\hline Amazonas & 58.220 & 56.285 \\
\hline Bahia & 2.922 .701 & 3.125 .766 \\
\hline Ceará & 1.606 .914 & 2.098 .893 \\
\hline Distrito Federal & 8.325 & 20.416 \\
\hline Espírito Santo & 28.348 & 37.826 \\
\hline Goiás & 113.683 & 201.173 \\
\hline Maranhão & 154.384 & 229.583 \\
\hline Mato Grosso & 193.704 & 549.484 \\
\hline Mato Grosso do Sul & 378.131 & 497.102 \\
\hline Minas Gerais & 116.796 & 228.306 \\
\hline Pará & 127.405 & 203.368 \\
\hline Paraíba & 343.844 & 433.032 \\
\hline Paraná & 548.998 & 613.934 \\
\hline Pernambuco & 753.218 & 1.622 .511 \\
\hline Piauí & 1.395 .960 & 1.392 .861 \\
\hline Rio de Janeiro & 21.100 & 48.489 \\
\hline Rio Grande do Norte & 389.706 & 583.661 \\
\hline Rio Grande do Sul & 4.812 .477 & 3.979 .258 \\
\hline Rondônia & 75.857 & 135.122 \\
\hline Roraima & - & - \\
\hline Santa Catarina & 207.099 & 293.349 \\
\hline São Paulo & 233.681 & 467.253 \\
\hline Sergipe & 96.422 & 168.674 \\
\hline Tocantins & 51.857 & 108.062 \\
\hline
\end{tabular}

Gouveia (2003) e Sepin (2010). 


\subsection{Caprinocultura}

O efetivo mundial de caprinos segundo estimativas da FAO (2000) é de 715,3 milhões de cabeças, com produção de carne em torno de 3,7 milhões de toneladas. O Brasil se destaca como o $10^{\circ}$ maior rebanho caprino do mundo, com cerca de 8 milhões de cabeças, somente a poucos anos vem melhorando seu rebanho, com seleção de raças ou tipos nativos e introdução de animais de raças especializadas na produção de carne, oferecendo melhores perspectivas econômicas para povos de regiões carentes. No Brasil, a maior concentração da espécie caprina está na região Nordeste, com $94 \%$ do rebanho.

A caprinocultura Brasileira em 2010 foi de 9,3 milhões de cabeças (Tabela 7), um aumento de $1,6 \%$ em relação a 2009. A região Nordeste do país mantém o maior efetivo de cabras, com mais de $90,0 \%$ do total nacional, tanto para produção de leite como de carne (IBGE, 2010).

No Nordeste, a maioria dos rebanhos caprinos, por serem explorados basicamente em sistemas de produção tradicional, apresenta baixa produtividade. Este índice está atrelado ao baixo nível de tecnologia empregado, que incorre em índices reprodutivos baixos, elevada mortalidade em todas as fases da criação acarretando uma baixa produtividade (FREITAS et al., 2005). O estado da Bahia apresenta a maior população caprina e a segunda maior ovina do Brasil (QUADROS, 2005).

Segundo a FAO (2004) o Brasil apresentou no ano de 2004, 1,16\% da criação de caprinos no mundo e detinha o décimo segundo maior rebanho, com 9,05 milhões de cabeças, apesar das condições bastante favoráveis que se mostram iguais ou até superiores às dos maiores criadores.

O abate mundial de caprinos, no período de 1991 a 2000, cresceu 7,5 \%. Em 1970, foram abatidos no Brasil 752 mil unidades caprinas e em 1992 esses números elevaram-se para 1.639 mil cabeças, representando um crescimento da ordem de $118 \%$, o valor atribuído ao consumo per capita no Brasil em 2003 foi de $0,125 \mathrm{~kg}$ (SAMPAIO et al., 2005). 
GODOI, C.R., SILVA, L.A. e SILVA, E.F.P. Desenvolvimento pecuário brasileiro no agronegócio mundial. PUBVET, Londrina, V. 6, N. 30, Ed. 217, Art. 1448, 2012.

TABELA 7 - Efetivo de caprinos no Brasil, por Unidade da Federação 2010.

\begin{tabular}{|c|c|}
\hline \multirow[b]{2}{*}{ BRASIL } & Número \\
\hline & 9.312 .784 \\
\hline \multicolumn{2}{|l|}{ ESTADOS } \\
\hline Acre & 18.203 \\
\hline Alagoas & 65.655 \\
\hline Amapá & 2.657 \\
\hline Amazonas & 18.649 \\
\hline Bahia & 2.847 .148 \\
\hline Ceará & 1.024 .594 \\
\hline Distrito Federal & 1.728 \\
\hline Espírito Santo & 17.897 \\
\hline Goiás & 39.737 \\
\hline Maranhão & 373.144 \\
\hline Mato Grosso & 40.246 \\
\hline Mato Grosso do Sul & 31.716 \\
\hline Minas Gerais & 118.572 \\
\hline Pará & 75.528 \\
\hline Paraíba & 600.607 \\
\hline Paraná & 181.984 \\
\hline Pernambuco & 1.735 .051 \\
\hline Piauí & 1.386 .515 \\
\hline Rio de Janeiro & 31.860 \\
\hline Rio Grande do Norte & 405.983 \\
\hline Rio Grande do Sul & 103.009 \\
\hline Rondônia & 14.598 \\
\hline Roraima & 9.245 \\
\hline Santa Catarina & 58.332 \\
\hline São Paulo & 65.078 \\
\hline Sergipe & 19.881 \\
\hline Tocantins & 25.167 \\
\hline
\end{tabular}

Fonte: Sepin (2010). 


\section{PRODUÇÃO DE CARNE MERCADO INTERNO E EXTERNO}

Segundo Bellaver (2002) tomando-se o elo da indústria de transformação, percebe-se que os desafios são muitos por sofrer influência de muitos fatores (dependência de insumos externos, transporte, impostos, mão de obra, taxas de cambio, etc.) que elevam o custo brasileiro. Para compensar a relativa ineficiência deste setor, o elo produtivo depara-se com enormes dificuldades para manter e/ou aumentar a produtividade, sempre buscando diminuir custos sem prejuízo na qualidade e assim tornar os produtos competitivos no mercado nacional e internacional. Cabe destacar que o mercado interno é extremamente importante para o elo produtivo, pois absorve cerca de $85 \%$ da produção brasileira de carnes que é superior a 16 milhões de ton.

No segmento de mercado internacional, bastante valorizado pelas indústrias, aparecem várias barreiras à exportação, restritivas ao uso de tecnologias para o aumento da produtividade animal, impostas por países importadores da Europa, Oriente Médio e Japão. Uma das maneiras de proteção aos produtores de países com tesouros fortes é a do subsídio. Outra forma de proteção de mercado respalda-se no princípio da precaução que, de uma forma indireta, protege o mercado doméstico dos países importadores, mesmo com custos mais elevados de produção. Dentre as restrições tecnológicas, destacam-se dois grupos que tem importância fundamental para o aumento da produtividade: os antimicrobianos promotores de crescimento de aves e suínos e os melhoradores de rendimento em carne nas carcaças de suínos (BELLAVER, 2002).

A produção de carne mundial em 2004 foi estimada pela FAO (Food and Agriculture Organization) em 258 milhões de toneladas, 2\% superior ao volume produzido em 2003. O maior crescimento foi verificado na América do Sul, onde a produção cresceu em media de 5\%, atingindo 31 milhões de toneladas. Na Ásia que normalmente representa cerca de $40 \%$ da produção mundial de carnes, o crescimento em 2004 foi de aproximadamente 2,4\%, o 
que representa somente metade do crescimento verificado em 2003. As estatísticas de produção mundial de carne bovina segundo levantamentos do USDA (2004) no período compreendido entre 2000 (50,345 milhões de toneladas) e 2004 (50,66 milhões de toneladas) temos praticamente uma estagnação na produção mundial de carne bovina. Este dado contradiz a previsão inicial do USDA de aumento de 1,4\% na produção (BRANCO \& MAIA, $S / D)$.

Nos anos 90 e início do novo século houve um significativo declínio no consumo de carne bovina, e tal fato se deu como resultado do surgimento da EEB (Encefalopatia Espongiforme Bovina) e de casos de aftosa em países, onde a doença estava erradicada (USDA, 2004). No entanto, as perspectivas e previsões apontam para um aumento de consumo nos próximos anos, já que medidas estão sendo tomada nos principais países importadores, como a Comunidade Econômica Européia (CEE) (BRANCO \& MAIA, S/D).

A alta verificada nos preços das carnes no ano de 2004 limitou o consumo global do produto e o consumo per capta deverá apresentar um pequeno crescimento, passando de 40,3 para 40,6 kg. O aumento anual deverá ser o mesmo para neste ano para países desenvolvidos e em desenvolvimento, mas o consumo anual per capta nos países em desenvolvimento, estimado em $29,7 \mathrm{~kg}$, continuará representando apenas $1 / 3$ dos países desenvolvidos (FAO, 2004).

Confirmando as previsões de 2004 para os dados de exportação de carne bovina dos principais países exportadores, o volume exportado foi da ordem de 6,9 milhões de toneladas, ou seja, aproximadamente $8 \%$ superior ao ano de 2003 (USDA, 2003). O Brasil se firmou no mercado internacional como o principal país exportador, superando, em volume, os Estados Unidos e Austrália. Com preços competitivos e investimentos em tecnologia o Brasil afeta significativamente a competição internacional no mercado de carne bovina. O volume exportado apresentou crescimento equivalente a $340 \% \mathrm{em} 7$ anos, passando de 287,16 mil toneladas em 1997 para 1,263 milhões toneladas em 2003, superando as melhores expectativas e as projeções do 
USDA, inclusive a de 2003 que foi de 1,175 milhões toneladas (BRANCO \& MAIA, S/D).

As exportações geraram 229 milhões de dólares em novembro de 2004 e 2,25 bilhões de dólares de janeiro a novembro deste mesmo ano, valores $42 \mathrm{e}$ $66 \%$ superiores, respectivamente, aos registrados nos períodos similares do ano anterior. O volume exportado em relação ao comercializado no mercado interno deve continuar aumentando uma vez que a produção brasileira esta crescendo e a demanda interna está estagnada em algo próximo a $37 \mathrm{~kg}$ per capita há praticamente três anos (BRANCO \& MAIA, S/D).

De acordo com as previsões otimistas de Morgan (1997) o efetivo do rebanho mundial deve experimentar um aumento de $100 \%$, o abate de bovinos triplicará e o consumo mundial de carne bovina será quatro vezes superior aos níveis atuais no ano de 2050, e que o maior aumento se dará fora das nações desenvolvidas. Segundo as informações deste autor, estes números serão atingidos como resultado da eliminação de todas as barreiras tarifárias e não tarifárias decorrentes da oferta de produto de alta qualidade, seguro para a saúde humana e parte indispensável de uma dieta que prolongue a vida humana. Os programas de rastreabilidade serão incrementados, aumentando significativamente nossa capacidade de prever e manejar a produção. Todos os segmentos da cadeia produtiva serão capazes de controlar seus processos o que produzirá um alimento de qualidade indiscutível.

As importações mundiais de carne bovina segundo os dados (USDA, 2004). Considerando o Brasil, constata-se que a maior parte da produção brasileira de carne bovina destina-se ao mercado interno. O consumo nacional está, atualmente, estimado em 6,56 milhões de toneladas (em equivalente carcaça), correspondendo à cerca de $81,2 \%$ da produção, e os restantes $18,8 \%$ são destinados ao mercado internacional. O crescimento consistente do movimento exportador nos últimos cinco anos permitiu maior sustentação dos preços internos, com as cotações do boi gordo passando a oscilar, 
praticamente, em função da sazonalidade (períodos de safra/entressafra das pastagens).

Branco \& Maia, (s/d) relata que a variação cambial e a maior demanda internacional pelo produto brasileiro favoreceram o crescimento acumulado do faturamento do segmento exportador, decorrência direta do maior volume comercializado, pois os preços médios mensais de exportação apresentaram-se praticamente estáveis. Essa evolução foi mais acentuada para a carne bovina in natura do que para a carne industrializada.

De acordo com Filho (2006) o Brasil detém o segundo maior rebanho comercial do mundo e é o maior exportador mundial. É ainda o segundo em quantidade de equivalente carcaça produzida, perdendo somente para os Estados Unidos da América do Norte em volume produzido. A produção de equivalente carcaça aumentou mais de $20 \%$, enquanto as exportações quadruplicaram. Aproximadamente 140 países compram hoje a carne bovina brasileira, a qual é literalmente comprada já que poucos esforços no sentido de promover nosso produto no exterior vêm sendo feitos, com exceção dos últimos dois anos quando um movimento ainda modesto de divulgação começou junto aos principais importadores. Os exportadores brasileiros terão que começar a se preocupar em divulgar o produto brasileiro se quiserem aumentar ou até mesmo manter o atual volume exportado, principalmente com a retomada das exportações de importantes concorrentes do Brasil, como a Austrália e a Argentina.

Segundo Bliska (1999), o consumo de carne bovina tem aumentado apenas em alguns países da Ásia, África e do Oriente Médio e em alguns países menos desenvolvidos. Na década de 80 , verificou-se ainda uma estagnação e até declínio no consumo de carne bovina nos países industrializados, um pequeno aumento no consumo da carne suína e uma expansão no consumo de aves.

Com o aumento da participação do país no mercado internacional e aumento da demanda interna por carne de qualidade este quadro está se alterando. No início dos anos 90 o Brasil exportava cerca de 5\% da sua 
produção como carne in natura. Hoje esse valor atinge aproximadamente $25 \%$ da produção total de carne exportada. Alguns frigoríficos chegam a exportar entre $60-90 \%$ de determinados cortes. A enorme diversificação da exportação nacional (mais de 140 países) ajuda, mas ainda assim há necessidade de melhorar e homogeneizar o abate, padronizar principalmente em peso, idade e grau de acabamento (FILHO, 2006; citado por (LANNA \& ALMEIDA, 2005).

Apesar de ser o líder mundial em tonelagem de carne bovina exportada, o país tem uma renda relativamente baixa, já que não exporta para os mercados de maior valor agregado, pois, além da questão da presença de aftosa nos rebanhos, a carne brasileira, segundo alguns importadores, não é considerada de boa qualidade. Mas o conceito de qualidade é questionável. Por exemplo, o zebuíno ficou "taxado" como produtor de carne de pouca maciez e com ausência de marmorização. Mas será que todos os importadores estão preocupados ou estão dispostos a pagar mais pela marmorização (FILHO, 2006).

A produção mundial das três principais carnes, apresentou um crescimento de $69,74 \%$ na sua totalidade comparando-se os volumes produzidos em 1973, num total de 109,939 milhões de toneladas, para 186,613 milhões de toneladas em 2000. Comparativamente, a carne suína no tocante à produção e consumo evoluiu ao nível aproximado do crescimento vegetativo da população mundial $79,21 \%$; portanto, registrando uma estabilidade na evolução, mas apresentando uma tendência de aumento em função dos problemas ocorridos na (União Européia) (EU) com a encefalopatia bovina espongiforme (B.S.E), febre aftosa e dioxina (BUTOLO, 2002).

A carne bovina entre produção e consumo apresentou-se abaixo do crescimento vegetativo da população mundial 30,29\%; que pode ser verificado na (Tabela 8), portanto evolução real negativa. Comparando com as outras carnes, a carne de frango, entre produção e consumo, evoluiu a taxas substancialmente e significativamente maiores que o crescimento vegetativo da população mundial 135,30\% (BUTOLO, 2002). 
TABELA 8 - Produção mundial das três principais carnes em milhões de toneladas e sua evolução.

\begin{tabular}{|c|c|c|c|c|c|}
\hline & & 1973 & & 2000 & \\
\hline $\begin{array}{l}\text { Tipo } \\
\text { carne }\end{array}$ & de Volume & $\begin{array}{l}\text { Participação } \\
\%\end{array}$ & Volume & $\begin{array}{l}\text { Participação } \\
\%\end{array}$ & $\begin{array}{l}\text { Variação no } \\
\text { período \% }\end{array}$ \\
\hline Suína & 50,794 & 46,20 & 91,030 & 48,78 & 79,21 \\
\hline Bovina & 41,509 & 37,76 & 54,085 & 28,98 & 30,29 \\
\hline Frango & 17,636 & 16,04 & 41,498 & 22,24 & 135,30 \\
\hline Total & 109,936 & 100,00 & 186,613 & 100,00 & 69,74 \\
\hline
\end{tabular}

Fonte USDA, ABIPECS, FAO/ONU (2000) Citada por (BUTOLO, 2002).

Segundo o Ministério da Agricultura, até 2020, a expectativa é que a produção nacional de carnes suprirá $44,5 \%$ do mercado mundial. Já a carne de frango terá $48,1 \%$ das exportações mundiais e a participação da carne suína será de 14,2\%, essas projeções indicam que o Brasil pode manter posição de primeiro exportador mundial de carnes bovina e de frango (MAPA, 2011).

Comparativamente ao bovino, o suíno e o frango tem um ciclo de vida mais curto (Tabela 9), fator que o transforma em um animal muito mais apto ao desenvolvimento, propiciando ganhos extraordinários ao setor, ou seja, no ganho de peso, redução do período de criação, no mais eficiente controle de doenças, na melhor conversão em carnes em um menor espaço de tempo e a custos cada vez mais acessíveis, com a opção maior da economia pela produção avícola (BUTOLO, 2002).

TABELA 9 - Produção mundial de carnes (em milhões de toneladas).

\begin{tabular}{lcccc}
\hline & 2004 & 2005 & 2006 & 2007 \\
\hline Suínos & 100,4 & 102,5 & 108,0 & 195,8 \\
Aves & 78,3 & 81,0 & 83,1 & 86,2 \\
Bovinos & 61,9 & 63,6 & 65,7 & 67,1 \\
Ovinos e & 12,1 & 12,9 & 13,5 & 13,8 \\
caprinos & 4,9 & 5,2 & 5,4 & 5,4 \\
Outras carnes & 257,6 & 265,2 & 275,7 & 278,3 \\
\hline \multicolumn{1}{c}{ Produção total } & & &
\end{tabular}

Fonte: FAO/UBA (2007-2008). 
De acordo com o último relatório da Organização das Nações Unidas para Agricultura e Alimentação (FAO, 2009) sob previsões para o mercado de carnes, como mostra a (Tabela 10) a recessão econômica desencadeada pela crise financeira no meio de 2008 teve um impacto severo no setor de carnes em 2009, apesar de um declínio nos preços dos principais ingredientes da dieta animal. De acordo com esse relato, a FAO revisou para baixo suas estimativas de produção mundial de carnes em 2009 para 282 milhões de toneladas, que é levemente a mais do que o nível de 2008. (FAO, 2009).

As previsões para o setor de carnes em 2010 são melhores, à medida que as principais economias estão retornando a um caminho positivo de crescimento. Os melhores retornos aos produtores deverão impulsionar a produção global de carnes para 286 milhões de toneladas. À medida que a demanda dos vários tipos de carnes se recupera, o comércio global deverá se recuperar em 2,5\%, para 23,7 milhões de toneladas no próximo ano. Da mesma forma, o consumo per capita de carnes pode aumentar levemente em 2010, consistente com suas melhores previsões de renda (FAO, 2009).

A qualidade da carne é dependente da aplicação de tecnologias originadas no melhoramento genético, na nutrição e na saúde animal. Esses conceitos devem estar em sintonia com a pressão dos consumidores e o direcionamento do mercado para qualidade da carne. Entretanto, a demanda sobre o setor de carnes deve ser balanceada com o desafio do aumento de produção para satisfazer os mercados interno e externo e ao mesmo tempo, reduzir o custo de produção, como forma de se manter competitivo no mercado (BELLAVER, 2003). 
GODOI, C.R., SILVA, L.A. e SILVA, E.F.P. Desenvolvimento pecuário brasileiro no agronegócio mundial. PUBVET, Londrina, V. 6, N. 30, Ed. 217, Art. 1448, 2012.

TABELA 10 - Mercado mundial de carne.

\begin{tabular}{lllll}
\hline & 2008 & 2009 & 2010 Prev. & $\begin{array}{l}\text { Var: 2010 sobre } \\
\text { 2009 }\end{array}$ \\
\cline { 2 - 5 } & \multicolumn{3}{c}{ Milhões de toneladas } \\
\hline Balanço mundial & $\mathbf{2 8 0 , \mathbf { 1 }}$ & $\mathbf{2 8 1 , 6}$ & $\mathbf{2 8 6 , \mathbf { 1 }}$ & $\mathbf{1 , 6}$ \\
\hline Produção & 65,1 & 64,3 & 64,0 & $-0,5$ \\
\hline Carne bovina & 91,8 & 91,9 & 94,2 & 2,5 \\
Carne de aves & 104,6 & 106,5 & 108,7 & 2,1 \\
Carne suína & 13,2 & 13,4 & 13,6 & 1,7 \\
Carne ovina & & & & $\mathbf{2 , 5}$ \\
Comércio & $\mathbf{2 4 , 5}$ & $\mathbf{2 3 , 1}$ & $\mathbf{2 3 , 7}$ & 2,0 \\
Carne bovina & 7,0 & 6,7 & 6,8 & 1,8 \\
Carne de aves & 10,2 & 9,8 & 10,0 & 4,2 \\
Carne suína & 6,1 & 5,5 & 5,7 & 1,8 \\
Carne ovina & 0,9 & 0,9 & 0,9 & \\
\hline
\end{tabular}

Indicadores de oferta e demanda

Consumo per capita de alimentos (kg/ano)

\begin{tabular}{lllll}
\hline Mundo & $\mathbf{4 2 , 0}$ & $\mathbf{4 1 , 7}$ & $\mathbf{4 1 , 9}$ & $\mathbf{0 , 4}$ \\
\hline Desenvolvidos & 83,1 & 81,8 & 82,2 & 0,4 \\
\hline $\begin{array}{l}\text { Em } \\
\text { desenvolvimento }\end{array}$ & 30,9 & 31,0 & 31,3 & 0,8 \\
\hline Fonte: FAO (2009), traduzidas e adaptadas pela Equipe BeefPoint. &
\end{tabular}

\section{CONSIDERAÇÕES FINAIS}

O crescimento do agronegócio brasileiro nas últimas décadas tem colocado o Brasil como líder mundial de exportações de carne e outros produtos não mencionados neste, se consolidando como celeiro do mundo.

\section{REFERÊNCIAS BIBLIOGRÁFICAS}

ABIPECS. Associação Brasileira da Indústria Produtora e Exportadora de Carne Suína. Relatório Anual 2004. Disponível em: <www.abipecs.com.br>. Acesso em:> 20/07/2010.

ANUALPEC. Anuário da pecuária brasileira. São Paulo: FNP Consultoria \& Comércio, 400p. 2004. 
ANUALPEC: Anuário da pecuária brasileira São Paulo: Finep Consultoria e Comercio, $p$. 281-332. 2002.

BARROS, N. N. \& VASCONCELOS, V. R. Produção de borregos para abate. Anais... III Simpósio Paraibano de Zootecnia, Universidade Federal da Paraíba, Centro de Ciências Agrárias, Areia, in CD-Rom. 2002.

BELLAVER, C. Práticas zootécnicas relacionadas com a qualidade da carne. $\mathbf{2}^{\circ}$. Simpósio de Ciência dos Alimentos da UFSC de 28 a 30/Maio/2003.

BELLAVER, C.; NONES, K. A importância da granulometria, da mistura e da peletização da ração avícula. Palestra apresentada no IV SIMPósIo Goiano de Avicultura. Goiânia- GO. 27/Abr/2002.

BLISKA, F. M. M. Impactos de alterações nas exportações brasileiras de carnes sobre a economia brasileira. Piracicaba. Tese de doutorado, ESALQ/USP. 217p. 1999.

BRANCO A. F. MAIA, F. J. Panorama mercado e comercialização na bovinocultura de corte.

BUTOLO, J. E. Qualidade de Ingredientes na Alimentação Animal. Colégio Brasileiro de Alimentação Animal. Campinas, 2002. 430p.

CIDRÃO, K. Produção de cordeiros em regime de pasto com suplementação mineral e protéica em cochos privativos. 2006. 60 f. Dissertação (Mestrado em Produção Integrada em Agroecossistemas) - Universidade de Marília, Coordenação de Aperfeiçoamento de Pessoal de Nível Superior, 2006.

COUTO, F. A. A. Dimensionamento do mercado de carne ovina e caprina no Brasil. Anais... II Simpósio Internacional sobre Caprinos e Ovinos de Corte, João Pessoa PB, 2003. p.71-81.

COUTO, F. A. A.; Dimensionamento do Mercado de Carne Ovina e Caprina no Brasil. IN: CNPq. Apoio à cadeia produtiva de ovino e caprinocultura brasileira. Relatório final. Brasília, 2001. p.10-15.

EUCLIDES FILHO, K. Produção de bovinos de corte e o trinômio genótipo-ambiente mercado. Campo Grande: EMBRAPA-CNPGC, 2000. p.6 (EMBRAPA Documentos, 85).

FAO prevê queda na produção de carne bovina em 30/12/2009. Disponível em: <http://www.beefpoint.com.br/?noticiaID $=59541 \&$ actA $=7 \&$ areaID $=15 \&$ sec

aoID=129> Acesso em: 18012010.

FAO WHO. Aspectos de segurança de alimentos geneticamente modificados de origem vegetal, FAO/OMS consulta 29 maio - 2 junho de 2000.World Health Organization, Genebra, Suíça 2000.

FAO. Estatística. FAO, 2007. Disponível em: HTTP:// faostat.fao.org>. acesso em: 02/11/2009.

FAO.FAOSTAT.2004.Disponível em:< http://www.fao.org/faostat/index_en.asp ,> acesso em: 10/10/2009.

FAO,2010.Disponível em: <http://economia.ig.com.br/empresas/agronegocio/ brasil+tera+missao+de+alimentar+o+mundo+diz+presidente+da+bunge/n1237724554876.h tml Acesso em: > 29/07/2010. 
FILHO, A. L. Produção de carne bovina no Brasil qualidade quantidade ou ambas. II SIMBOI Simpósio sobre Desafios e Novas Tecnologias na Bovinocultura de Corte, 29 a 30. Abr.BrasíliaDF. 2006.

FREITAS, J.V.F.; TEIXEIRA, D.I.A.; LOPES-JUNIOR, E.S.; PAULA, N.R.O.; ALMEIDA, A.P. Manejo reprodutivo de caprinos e ovinos. Do campus para o campo: Tecnologia para produção ovinos e caprinos. 1 ed. Fortaleza: Gráfica Nacional, 2005. p.241-263.

GARCIA, I. F. F.; BONOGURIO, S.; PEREZ, J. R. O. Comercialização da carne ovina. Encontro mineiro de ovinocultura. Lavras. Anais... Lavras: UFLA, 2006. p.15.

GONÇALVES, R. G.; PALMEIRA, E. M. "Suinocultura Brasileira" en Observatorio_de la Economía Latinoamericana, Número 71, 2006. Texto completo, disponível em:< http://www.eumed.net/cursecon/ecolat/br/index.htm> Acesso em: 19/07/2010.

Gouveia A. M. G. Políticas de controle de doenças em caprinos e ovinos. Anais... PECNORDESTE VII seminário nordestino de pecuária, Fortaleza, 2003. P. 97-138.

GUANZIROLI, C. E. Agronegócio no Brasil: perspectivas e limitações Abril/2006.Disponível em: < http://www.uff.br/econ/download/tds/UFF_TD186.

pdf> Acesso em:19/07/2010.

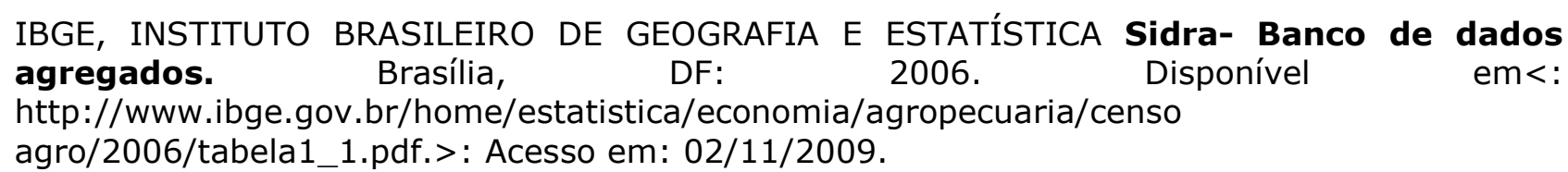

IBGE INSTITUTO BRASILEIRO DE GEOGRAFIA E ESTATÍSTICA - Indicadores agropecuários, Rebanho bovino no Centro-Oeste, 2005. Disponível em: http://www.ibge.gov.br/home/presidencia/noticias/noticia_visualiza.php?id_noticia=1039.>. Acesso em: 18/01/2010.

IBGE INSTITUTO BRASILEIRO DE GEOGRAFIA E ESTATÍSTICA. 2007. Disponível em: http://www.ibge.gov.br/home/presidencia/default_ant.php. Acesso em: 18/01/2010.

JUNIOR, G. A. A. et al. Desempenho, características de carcaça e resultados econômicos de cordeiro criados em creep feeding com silagem de grãos úmidos de milho. Revista Brasileira de Zootecnia, v. 33, n. 4, p. 1048 -1059. 2004.

IBGE INSTITUTO BRASILEIRO DE GEOGRAFIA E ESTATÍSTICA 2010. Disponível em:http://www.ibge.gov.br/home/presidencia/noticias/noticia_visualiza.php?id_noticia=2002\& id_pagina =1\&titulo=PPM-2010:-Rebanho-bovino-nacional-cresce-2,1\%-e-chega-a-209,5milhoes-de-cabecas. Acesso em: $>12 / 12 / 2011$.

LANNA, D.P.D.; ALMEIDA, R. Produção de Bovinos: Terminação em Confinamento. Revista Visão Agrícola, 2005.

MAPA. Agronegócio Brasileiro: 2004. Uma Oportunidade de Investimentos. Disponível em:<http://www.agricultura.gov.br/portal/page?_pageid=33,9687

07\&_dad=portal\&_schema=PORTAL> Acesso em: 19/07/2010.

MAPA. MINISTÉRIO DA AGRICULTURA PECUÁRIA E ABASTECIMENTO 2011. Disponível em:< http://www.agricultura.gov.br/animal/mercado-interno>. Acesso em: 12/12/2011.

MEDEIROS, J. X. Situação atual das cadeias produtivas. In: Apoio a cadeia produtiva da ovino e caprinocultura brasileira. Relatorio Final. MCT/CNPq. Brasilia. p.55. 2001. 
MORGAN, W. World beef trade expected to expand by 20 fold by 2050 . Disponível em:<www.morgan-consulting.com> Acesso em: 30/01/2010. 1997.

MOTTA, O. S. PIRES, C. C. SILVA, J. H. S., et. al., Avaliação da carcaça de cordeiros da raça texel sob diferentes métodos de alimentação e pesos de abate. Ciência Rural, Santa Maria, v.31, n.6, p.1051-1056.2001.

NOGUEIRA FILHO, A. Ações de fomento do banco do nordeste e potencialidade da caprinoovinocultura. n: Simpósio Internacional sobre Caprinos e Ovinos de Corte, 2003. João Pessoa PB. EMEBA. P. 43-55. 2003.

OTTO, C.; SÁ, J. L. WOEHL, et al. Estudo econômico da terminação de cordeiros a pasto e em confinamento. Revista do Setor de Ciências Agrárias, v. 16, n. 1/2, p. 223-227. 1997.

PEREIRA, M. A.; LIMA, J. E. Oferta de carne bovina brasileira para exportação no período de 1980 a 1998. Anais... do XXXVIII Congresso Brasileiro de Economia e Sociologia Rural, Rio de Janeiro. Jul/ago, 2000. p.10.

QUADROS, D. G. SISTEMAS DE PRODUÇÃO DE OVINOS E CAPRINOS DE CORTE, Salvador BA, Nov. 2005. Disponível

em:<http://www.neppa.uneb.br/textos/publicacoes/cursos/sistemas_producao_corte.pdf >Ace sso em: $15 / 02 / 2010$.

RODRIGUES, G.V. Plano setorial bovinocultura de corte. Minas Gerais 2008. Disponívelem:<http://www.conselhos.mg.gov.br/uploads//20/Plano\%20Setorial\%20-

\%20Bovinocultura\%20de\%20Corte.pdf> Acesso em: 18/01/2010.

ROPPA, L. Tendências da suinocultura mundial e as oportunidades brasileiras. In: Anualpec, 2002, São Paulo/SP FNP Consultoria e comercio Ltda, 2002. 281p.

SAMPAIO, B.; SAMPAIO, Y.; LIMA, R. C.; AIRES, A.; SAMPAIO, G. R.; Perspectivas para a Caprinocultura no Brasil: o Caso de Pernambuco. In: XLIV Congresso da Sociedade Brasileira de Economia e Sociologia Rural, 2006, Fortaleza. Questões Agrárias, Educação no Campo e Desenvolvimento, 2006.

SEPIN-Superintendência de Estatística, pesquisa e Informações Socioeconômicas 2011. Disponível em:<http://www.seplan.go.gov.br/sepin/

Acesso em: $>$ 12/12/2011.

SILVA, R. R. O agronegócio brasileiro da carne caprina e ovina. Salvador: 2002.

SINDIRAÇÕES. Indústria de ração animal recua 0,5\% em 2009. SP. 11 de dez. 2009.Disponível em:<http://www.paginarural.com.br/noticia/124516/Industria -de-racao-animal-recua-05-em-2009-diz-sindiracoes>Acesso em: 28/01/2010.

SINDIRAÇÕES. Manual, Gestão do Alimento Seguro. Versão 3.0, p. 36. out, 2006.Disponível em:<http://www.paginarural.com.br/noticia/124516/Industria

-de-racao-animal-recua-05-em-2009-diz-sindiracoes>Acesso em: 8/01/2010.

SINDIRAÇÕES. 2011. Disponível em:< http://www.avisite.com.br/clipping/ default.asp?codnoticia =17953: Acesso em: $>$ 15/12/2011.

UBA, UNIÃO BRASILEIRA DE AVICULTURA: Relatório Anual 2007/2008. Disponível em: <http://www.uba.org.br/site3/arquivos/relatorio_07_08.pdf> Acesso em: 03/03/2010. 
USDA. 2004 SERVIÇO DE PESQUISA ECONÔMICA DO DEPARTAMENTO DE AGRICULTURA DOS ESTADOS UNIDOS. Disponível em:< www.fas.usda.gov/dlp/circular/2004/0410LP/beefoverview.html: > Acesso em: 30/01/2010.

USDA. 2003 SERVIÇO DE PESQUISA ECONÔMICA DO DEPARTAMENTO DE AGRICULTURA DOS ESTADOS UINÃO. WWW.fas.usada.gov/dlp/circular/2003/

03-10LP/beefoverview.html> Acesso em: 30/01/2010. 